\title{
Characterization of the Calcium-Fluoroaluminosilicate Glass Prepared by a Non-Hydrolytic Sol-Gel Route for Future Dental Application as Glass Ionomer Cement
}

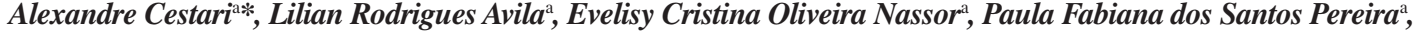 \\ Paulo Sergio Calefi, Katia Jorge Ciuffi, Shirley Nakagaki ${ }^{\mathrm{b}}$, Antonio Carlos Pereira Gomes ${ }^{\mathrm{a}}$, Eduardo Jose Nassar ${ }^{\mathrm{a} *}$ \\ ${ }^{a}$ University of Franca, CP 82, 14404-600 Franca - SP, Brazil \\ ${ }^{\mathrm{b}}$ Department of Chemistry, Federal University of Paraná - PR, Brazil \\ Av. Dr. Armando Salles de Oliveira, 201, 14404-600 Franca - SP, Brazil
}

Received: September 3, 2008; Revised: March 10, 2009

\begin{abstract}
Glass ionomer cements are widely employed in dentistry due to their physical, biological and mainly anti-caries properties. Glass ionomers consist of an aluminosilicate glass matrix modified with other elements, and they contain large quantities of fluorine. In this study, we report on the preparation of calcium-fluoroaluminosilicate glasses by a nonhydrolytic sol-gel route as an alternative approach to obtaining alumina-silica matrices. The glass powders were prepared via the non-hydrolytic sol-gel method, by mixing $\mathrm{AlCl}_{3}, \mathrm{SiCl}_{4}, \mathrm{CaF}_{2}, \mathrm{AlF}_{3}, \mathrm{NaF}$, and $\mathrm{AlPO}_{4}$. The powders were studied by thermal analysis (TG/DTA/DSC), photoluminescence (PL), nuclear magnetic resonance $\left(\mathrm{NMR}^{27} \mathrm{Al}{ }^{29} \mathrm{Si}\right)$, and $\mathrm{X}$ ray diffraction (XRD). TG/DTA/DSC analyses revealed a constant mass loss due to structural changes during the heating process, which was confirmed by NMR and PL. A stable aluminosilicate matrix with potential future application as a glass ionomer base was obtained.
\end{abstract}

Keywords: aluminosilicate, dental cement, glass ionomer, $N M R^{27} \mathrm{Al}-{ }^{29} \mathrm{Si}$

\section{Introduction}

Glass ionomer cements were firstly developed by Wilson and Kent in 1969. Due to their sustained fluoride release, they have found use as a restorative dental material with long-term adhesion to the dental structure, good biocompatibility, and cariostatic properties. These cements became commercially available in Europe in 1975 and since then they have been modified for use in specific clinical situations ${ }^{1-3}$. The glass ionomer consists in an aluminum and silicon matrix comprising an amorphous structure ${ }^{2}$, which renders glass ionomer cements their special mechanical strength properties (compressive, diametral tensile, and biaxial flexural strength) ${ }^{4}$.

Nowadays, cement formulations allow for their application as base or dentine substitute under a composite resin, luting cement in crown and bridgework, lining cement under a metal restoration, long-term sealant over an active carious lesion, and restoration material in its own right ${ }^{5,6}$.

The commercial glass powder is prepared by melting $\mathrm{SiO}_{2}, \mathrm{Al}_{2} \mathrm{O}_{3}$, $\mathrm{AlF}_{3}, \mathrm{CaF}_{2}, \mathrm{NaF}$, and $\mathrm{AlPO}_{4}$ at temperatures ranging from 1,200 to $1,550{ }^{\circ} \mathrm{C}$. After the melting process, the homogeneous glass is ground to produce the powder ${ }^{2,6}$, while the cement is prepared by mixing glass powder with poly(alkenoic acids) $)^{7-11}$.

The nonhydrolytic sol-gel route is an alternative process for the production of multicomponent oxide materials with chemical, physical and thermal properties that cannot be obtained by the hydrolytic sol-gel route and fusion methodologies ${ }^{12,13}$. This alternative method is based on the condensation between an alkoxide and a metal halide. The alkoxide can be added to the reaction or obtained in situ by reaction of a metal chloride with oxygen donors; i.e., ethers or alcohols, in the absence of water (Scheme 1) $)^{14-16}$.

$$
\begin{aligned}
& \mathrm{M}-\mathrm{Cl}+\mathrm{R}-\mathrm{O}-\mathrm{R} \rightarrow \mathrm{M}-\mathrm{OR}+\mathrm{RCl} \\
& \mathrm{M}-\mathrm{Cl}+\mathrm{ROH} \rightarrow \mathrm{M}-\mathrm{OR}+\mathrm{HCl}
\end{aligned}
$$

The alkoxide is condensed with a metal chloride, to form a metal oxide (Scheme 2$)^{14}$.

$$
\mathrm{M}-\mathrm{Cl}+\mathrm{M}-\mathrm{OR} \rightarrow \mathrm{M}-\mathrm{O}-\mathrm{M}+\mathrm{RCl}
$$

This route requires low temperatures, close to $110^{\circ} \mathrm{C}$, and it is advantageous because the products are more homogeneous, the method is easier to reproduce, no solvents are required, and the formation of residual Metal-OH groups is reduced ${ }^{15,17,18}$.

In this work, the calcium-fluoroaluminosilicate glass was prepared in oven-dried glassware. To this end, $\mathrm{AlCl}_{3}, \mathrm{SiCl}_{4}, \mathrm{CaF}_{2}, \mathrm{AlF}_{3}, \mathrm{NaF}$, $\mathrm{AlPO}_{4}$ and ethanol were reacted in reflux under argon atmosphere, and europium (III) chloride was added as a structural probe. The powder mixtures were dried at $50{ }^{\circ} \mathrm{C}$ and heat-treated at $1,000{ }^{\circ} \mathrm{C}$ for 4 hours. The synthesis and structure of the powders were studied by thermal analysis (TG/DTA/DSC), photoluminescence (PL), nuclear magnetic resonance $\left(\mathrm{NMR}^{27} \mathrm{Al}-{ }^{29} \mathrm{Si}\right)$, and $\mathrm{X}$ ray diffraction $(\mathrm{XRD})$.

\section{Experimental}

The nonhydrolytic sol-gel route described in the literature ${ }^{19}$ and modified by Ciuffi ${ }^{20}$ was employed in the preparation of the calcium-fluoroaluminosilicate glass. The glasses were prepared in oven-dried glassware.

The reagents $\mathrm{AlCl}_{3}, \mathrm{AlF}_{3}, \mathrm{CaF}_{2}, \mathrm{NaF}, \mathrm{SiCl}_{4}$, and $\mathrm{AlPO}_{4}$ in weight percentages of $28.6,1.6,15.7,9.3,41.9$, and 3.8 , respectively, were added to $40 \mathrm{~mL}$ of anhydrous ethanol and $10 \mathrm{~mL}$ of diisopropyl ether, used as oxygen donors. One percent of $\mathrm{EuCl}_{3}$ in weight was added as structural probe. The reaction was kept under reflux and magnetic stirring for 4 hours in inert argon atmosphere. The condenser was placed in a thermostatic bath at $-5^{\circ} \mathrm{C}$. After the reflux, the mixture was cooled and aged overnight in the mother liquor at room temperature (RT), and precipitation continued through aging in the mother liquor ${ }^{20}$. The solvent was then removed under vacuum. The powder was dried for one week at $50{ }^{\circ} \mathrm{C}$, resulting in a fine white powder.

Thermal Analysis (TG/DTA/DSC) was carried out in a thermal analyzer (TA - Instruments - SDT Q600 - Simultaneous DTA-TG) under nitrogen atmosphere, at a heating rate of $20^{\circ} \mathrm{C} / \mathrm{min}$, from 25 to $1,500^{\circ} \mathrm{C}$. The luminescence data were obtained on a Spex Fluorolog II spectrofluorometer, at room temperature. The emission was collected at $22.5^{\circ}$ (front face) from the excitation beam. The material was

*e-mail: alecestari@yahoo.com.br, ejnassar@unifran.br 
submitted to ${ }^{29} \mathrm{Si}$ and ${ }^{27} \mathrm{Al} \mathrm{NMR}$ analysis $(59.5 \mathrm{MHz})$ in an INOVA 300 Varian spectrophotometer, using silicon nitride as reference. $\mathrm{X}$ ray diffractograms (XRD) were obtained using a Siemens ${ }^{\circledR}$ (D 5005) $\mathrm{X}$ ray diffractometer under $\mathrm{Cu} \mathrm{K}_{\alpha}$ radiation.

\section{Results and Discussion}

Figure 1 depicts the DTA and DSC curves of the material prepared in this work. These curves reveal the presence of an exothermic peak at $932^{\circ} \mathrm{C}$, which is characteristic of the glass crystallization temperature $\left(\mathrm{T}_{c}\right)$, and can be attributed to the transition from the amorphous to the crystalline system, as indicated by $\mathrm{X}$ ray analysis.

The TG curves obtained for the sample before it was submitted to thermal treatment reveal a considerable mass loss between 30 and $400{ }^{\circ} \mathrm{C}$, which is attributed to ethanol and water molecules.

Figure 2 shows the XRD patterns of the calcium-fluoroaluminosilicate glass dried at $50{ }^{\circ} \mathrm{C}$ and heat-treated at $1,000{ }^{\circ} \mathrm{C}$. The $\mathrm{SiO}_{2}$ $\mathrm{Al}_{2} \mathrm{O}_{3}-\mathrm{CaO}$ or $\mathrm{SiO}_{2}-\mathrm{Al}_{2} \mathrm{O}_{3}-\mathrm{CaO}-\mathrm{CaF}_{2}$ systems studied by Bertolini et al. ${ }^{21}$ presented the anorthite phase $\left(\mathrm{CaAl}_{2} \mathrm{Si}_{2} \mathrm{O}_{8}\right)$ when heat-treated at $1,020^{\circ} \mathrm{C}$. In the present work, an amorphous structure predominates in the system dried at $50{ }^{\circ} \mathrm{C}$, confirming the glass structure. As

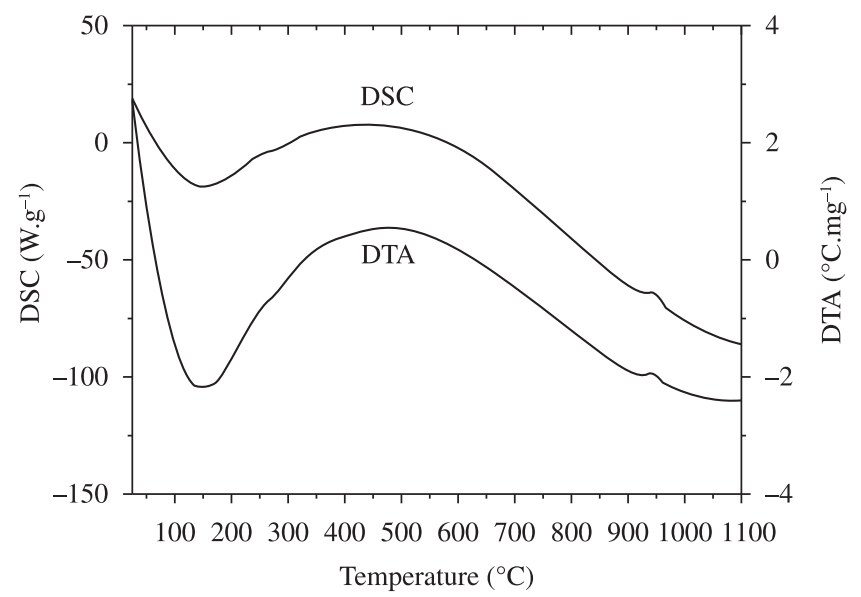

Figure 1. DTA and DSC curves for the calcium-fluoroaluminosilicate glass.

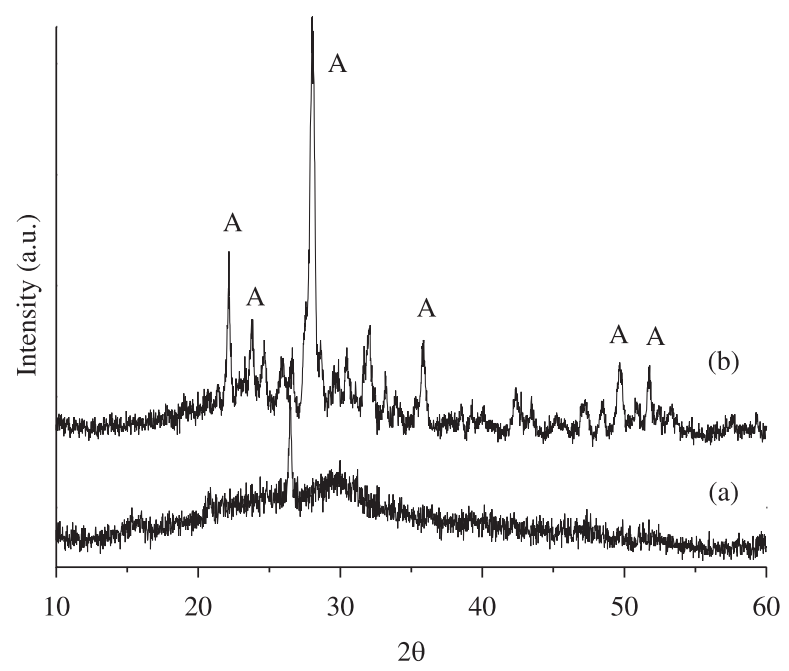

Figure 2. Diffractogram of the sample heat-treated at: (a) $50^{\circ} \mathrm{C}$, and (b) $1,000{ }^{\circ} \mathrm{C}$; anorthite (A). for the material heat-treated at $1,000{ }^{\circ} \mathrm{C}$, it displays defined peaks characteristic of the anorthite crystalline structure.

The ${ }^{27} \mathrm{Al}$ NMR spectrum indicates the aluminum coordination. Figure 3 presents the NMR spectrum of the calcium-fluoroaluminosilicate glass dried at $50{ }^{\circ} \mathrm{C}$ and of the same glass heat-treated at $1,000{ }^{\circ} \mathrm{C}$.

The central transition (CT) frequency of the spectrum of a quadrupolar nucleus of half integer spin, such as ${ }^{27} \mathrm{Al}(\mathrm{I}=5 / 2)$, depends on the orientation of each crystalline in the static magnetic field to the second order in perturbation theory. The quadrupolar interaction between the nuclear electric quadrupole moment $(\mathrm{eQ})$ and the electric field gradient of the nucleus (eq), arising from any lack of symmetry in the local electron distribution, is described by the quadrupolar coupling constant $\mathrm{Cq}\left(\mathrm{e}^{2} \mathrm{qQ} / \mathrm{h}\right)$ and the symmetry parameter $\eta$. It should be noted that disordered materials such as glasses have a wide range of interatomic distances, so CT line broadening occurs due to the $\delta^{\text {iso }}$ distribution and quadrupolar interactions ${ }^{22}$.

After the material was heat-treated at $1,000{ }^{\circ} \mathrm{C}$, a single peak corresponding to $\mathrm{Al}^{(\mathrm{VI})}$ predominated at $0.0 \mathrm{ppm}$, indicating that a structural change in the coordination state of aluminum occurred. When $\mathrm{Al}$ atoms are in tetrahedral coordination $\mathrm{Al}^{(\mathrm{IV})}$, their chemical shifts vary from 55 to $80 \mathrm{ppm}$, as indicated in Figure 2. Chemical shifts in the range of -10 to $10 \mathrm{ppm}$ correspond to coordinated octahedral $\mathrm{Al}^{(\mathrm{VI})}{ }^{17-19}$. The spectra of the two samples display three peaks, namely at 10.4, 59.4 and $140.1 \mathrm{ppm}$, which are characteristic of $\mathrm{Al}^{(\mathrm{VI})}, \mathrm{Al}^{(\mathrm{IV})}$, and spinning side bands ${ }^{23}$, respectively. Although some authors have reported the presence of $\mathrm{Al}^{(\mathrm{V})}$ atoms with chemical shifts at $20 \mathrm{ppm}^{8}$, we did not observe this peak. The dominant species in the sample dried at $50{ }^{\circ} \mathrm{C}$ corresponds to $\mathrm{Al}^{(\mathrm{IV})}$.

To be employed as a glass ionomer cement base, calciumfluoroaluminosilicate should display considerable basicity. To this end, the $\mathrm{AlO}_{4}$ tetrahedron should bind to $\mathrm{a} \mathrm{SiO}_{4}$ tetrahedron via an oxygen atom. When $\mathrm{Al}^{3+}$ ions are incorporated into an amorphous $\mathrm{SiO}_{2}$ network, it acquires a negative charge that is counter-balanced by cations, such as $\mathrm{Ca}^{2+}$ and $\mathrm{P}^{5+}$. Phosphorus is present as tetrahedral $\mathrm{PO}_{4}$ adjacent to tetraedral $\mathrm{AlO}_{4}$ (forming $\mathrm{AlPO}_{7}$ ) in the network as a result of the charge balance between the $\mathrm{Al}^{3+}$ and $\mathrm{P}^{5+}$ ions.

The bond established between the aluminum and silicon tetrahedra via the same oxygen atom is protophylic, as in the case of non-bonding oxygens. This makes the vitreous network susceptible

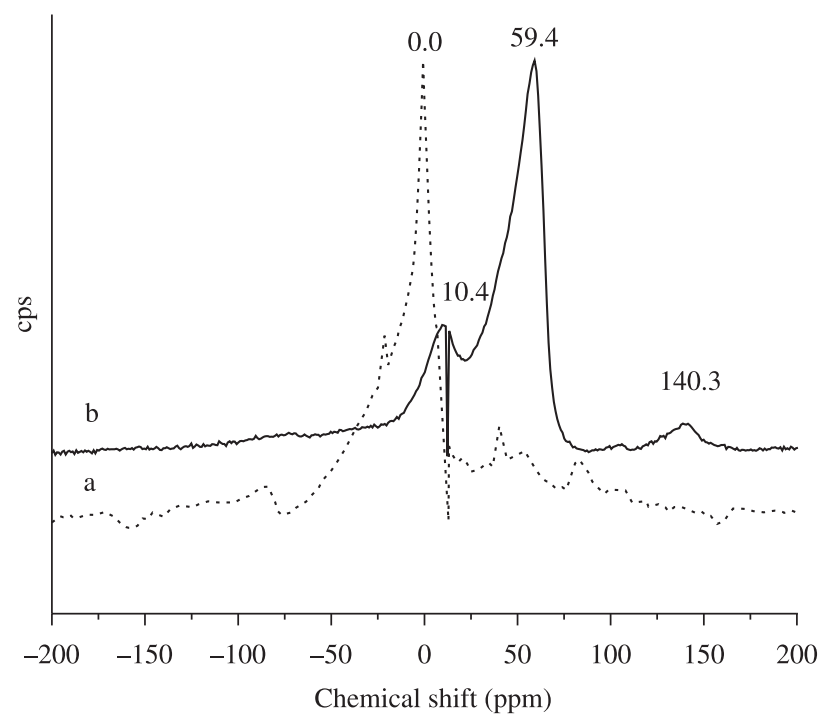

Figure 3. ${ }^{27} \mathrm{Al}$ NMR spectrum of the sample dried at $50{ }^{\circ} \mathrm{C}$ and treated at $1,000{ }^{\circ} \mathrm{C}$. 
to acid attack, which is desirable for materials based on calciumfluoroaluminosilicates if they are to be used as glass ionomer cement base. In fact, the material dried at $50{ }^{\circ} \mathrm{C}$ presents a chemical shift value typical of tetracoordinated aluminum, which is one of the requirements for dental cement bases.

The exact location of the chemical shifts due to $\mathrm{Al}^{(\mathrm{IV})}$ between 50 and $60 \mathrm{ppm}$ depend on the Al:P molar ratio. A chemical shift at $60 \mathrm{ppm}$ for $\mathrm{Al}^{(\mathrm{IV})}$ has been found for model glasses based on $\mathrm{SiO}_{2}$ $\mathrm{Al}_{2} \mathrm{O}_{3} \mathrm{CaOCaF}_{2}$, and at about $50 \mathrm{ppm}$ in glasses containing phosphate at an Al:P molar ratio of $2: 1^{23}$. The $\mathrm{Al}: \mathrm{P}$ molar ratio in our sample is approximately 10 , which is higher than the one encountered in commercial glasses. In our case, this chemical shift is very difficult to observe because of the lower prevalence of Al-O-P bonds.

The ${ }^{29} \mathrm{Si}$ NMR analysis allows for investigation of the chemical environment of silicon atoms in silicates. Si-atoms are generally bound to four oxygen atoms in silicates, which can be represented by a tetrahedron whose corners link to other tetrahedra. The $\mathrm{Q}^{\mathrm{n}}$ notation serves to describe the substitution pattern around a specific silicon atom, with Q representing a silicon atom surrounded by four oxygen atoms and $n$ indicating the connectivity ${ }^{24}$. Figure 4 depicts the ${ }^{29} \mathrm{Si}$ NMR spectrum of the sample dried at $50{ }^{\circ} \mathrm{C}$.

The material displays a peak at $-100 \mathrm{ppm}$ and a shoulder at $-110 \mathrm{ppm}$, which can be attributed to $\mathrm{Si}$ atoms $\mathrm{Q}^{4}$ and $\mathrm{Q}^{4}$ or $\mathrm{Q}^{3}$, respectively. Figure 5 illustrates the $\mathrm{Q}^{3}$ and $\mathrm{Q}^{4}$ structure.

The chemical shift indicates the environment around the $\mathrm{Si}$ atoms in the glass. The commercial calcium-fluoroaluminosilicate glass presents a broad peak between -90 and $-99 \mathrm{ppm}^{8}$, so our material exhibits a vitreous lattice.

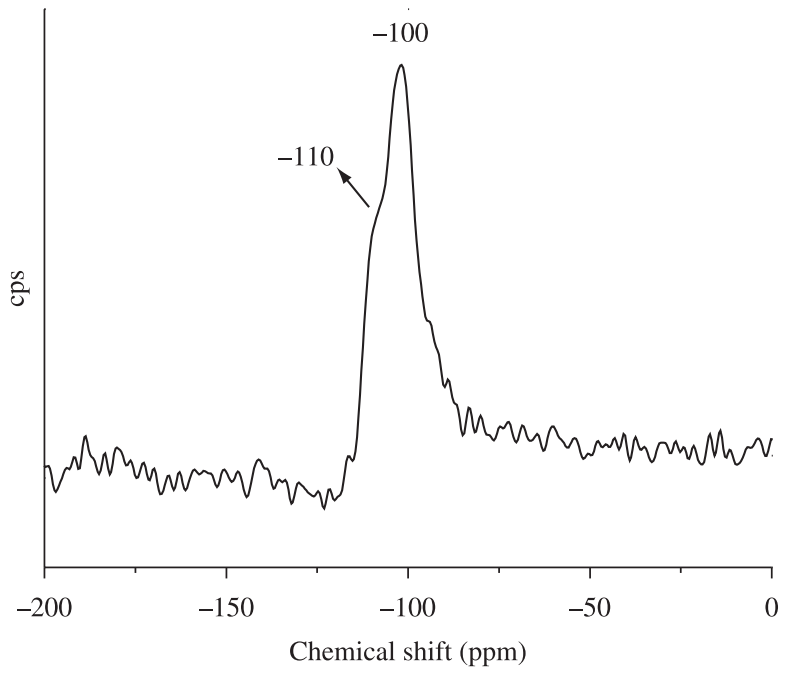

Figure 4. ${ }^{29} \mathrm{Si}$ NMR spectrum of the sample dried at $50{ }^{\circ} \mathrm{C}$.

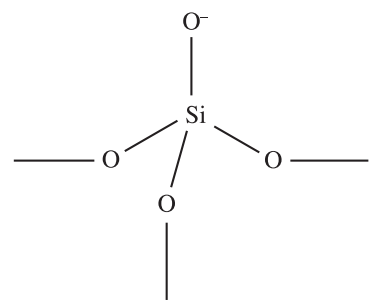

$Q^{3}$

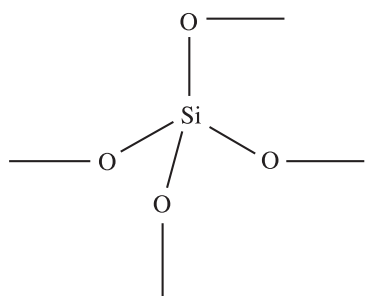

$Q^{4}$
Figure 5. Schematic representation of the $\mathrm{Q}^{3}$ and $\mathrm{Q}^{4}$ structures.
The number of nearest neighboring aluminum atoms is given in brackets; thus, $\mathrm{Q}^{4}(3 / 4 \mathrm{Al})$ and $\mathrm{Q}^{4}(1 / 2)^{22}$ are the structure represented in Figure 6.

The chemical shift ranges overlap, so the resonances in Fuji II cement (commercial glass) at $-87 \mathrm{ppm}$ may be due to $\mathrm{Q}^{4}(3 / 4 \mathrm{Al})$, while the resonances at $-92 \mathrm{ppm}$ may be due to $\mathrm{Q}^{4}(3 \mathrm{Al})$, at $-99 \mathrm{ppm}$ to $\mathrm{Q}^{4}$ $(1 / 2 \mathrm{Al})$, and at $-109 \mathrm{ppm}$ to $\mathrm{Q}^{4}(0 \mathrm{Al})^{22}$. In this case, the chemical shifts at -110 and $100 \mathrm{ppm}$ may be due to the $\mathrm{Si}$ atoms $\mathrm{Q}^{4}(1 / 2 \mathrm{Al})$ and $\mathrm{Q}^{4}(0 \mathrm{Al})$, because the $\mathrm{Al}$ :Si molar ration is less than 1 .

Figure 7 shows the ${ }^{29} \mathrm{Si}$ NMR of the sample heat-treated at $1,000{ }^{\circ} \mathrm{C}$ for 4 hours. Only one peak at $-88 \mathrm{ppm}$ is observed, which is attributed to $\mathrm{Q}^{4}(3 / 4 \mathrm{Al})$ site $\mathrm{Si}$ atoms due to the structural rearrangement of the aluminosilicate crystalline structures and is consistent with our $\mathrm{X}$ ray data.

Figure 8 presents the excitation spectrum of the $\mathrm{Eu}^{3+}$ ion in the sample treated at $1,000{ }^{\circ} \mathrm{C}$. The line observed in this spectrum can be assigned to the transition between the ${ }^{7} \mathrm{~F}_{0}$ and the ${ }^{5} \mathrm{~L}_{6},{ }^{5} \mathrm{~L}_{7},{ }^{5} \mathrm{D}_{4}$, ${ }^{5} \mathrm{D}_{3},{ }^{5} \mathrm{D}_{2}$, and ${ }^{5} \mathrm{D}_{1}$ levels

Figure 9 depicts the emission spectra of the $\mathrm{Eu}^{3+}$ ion recorded in the 550-720 nm range for the sample treated at $1,000{ }^{\circ} \mathrm{C}$ and excited at 394 and $462 \mathrm{~nm}$.

Excitation and emission of the $\mathrm{Eu}^{3+}$ ion in the material dried at $50{ }^{\circ} \mathrm{C}$ could not be observed because of the quenching caused by the vibrational mode of the solvent molecules in the material. This fact also occurred when the nonhydrolytic sol-gel route was employed for preparation of yttrium-alumina-garnet (YAG) at room temperature ${ }^{25,26}$ and alumina oxide ${ }^{27}$.

The emission spectra obtained by excitation in the ${ }^{5} \mathrm{D}_{0} \rightarrow{ }^{5} \mathrm{~L}_{6}$ and ${ }^{5} \mathrm{D}_{0} \rightarrow{ }^{5} \mathrm{D}_{2}$ transition of $\mathrm{Eu}^{3+}$ ions at 394 and $462 \mathrm{~nm}$, respectively, are composed by the ${ }^{5} \mathrm{D}_{0} \rightarrow{ }^{7} \mathrm{~F}_{\mathrm{J}}(\mathrm{J}=0,1,2,3$ and 4$)$ emission lines<smiles>[AlH2]O[Si](O[AlH2])(O[AlH2])O[AlH2]</smiles>

$\mathrm{Q}^{4}(3 / 4 \mathrm{Al})$<smiles>[AlH2]O[Si](O[SiH3])(O[SiH3])O[SiH3]</smiles>

$\mathrm{Q}^{4}(1 / 2 \mathrm{Al})$
Figure 6. Schematic representation of the $\mathrm{Q}^{4}(3 / 4 \mathrm{Al})$ and $\mathrm{Q}^{4}(1 / 2 \mathrm{Al})$ structures.

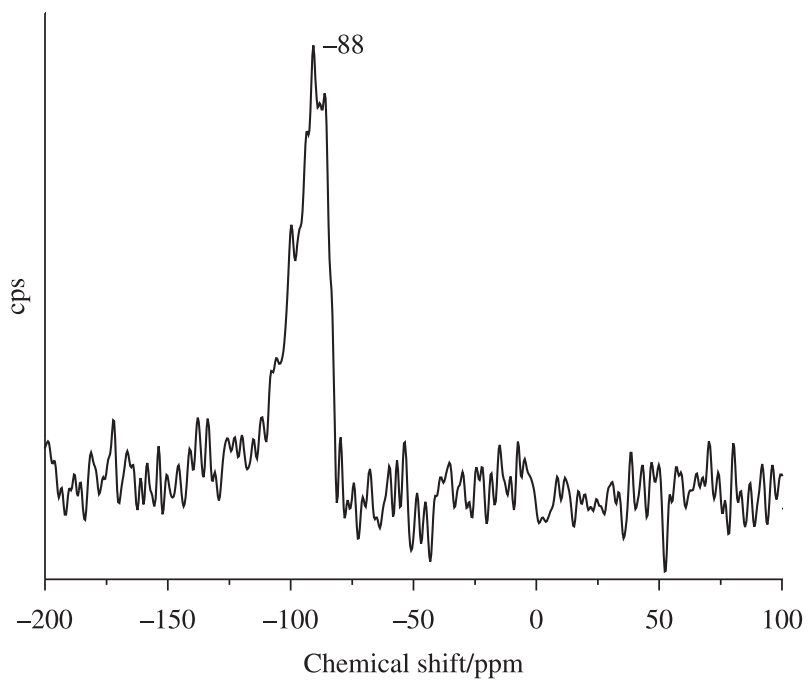

Figure 7. ${ }^{29} \mathrm{Si}$ NMR spectrum of the sample heat-treated at $1,000{ }^{\circ} \mathrm{C}$. 


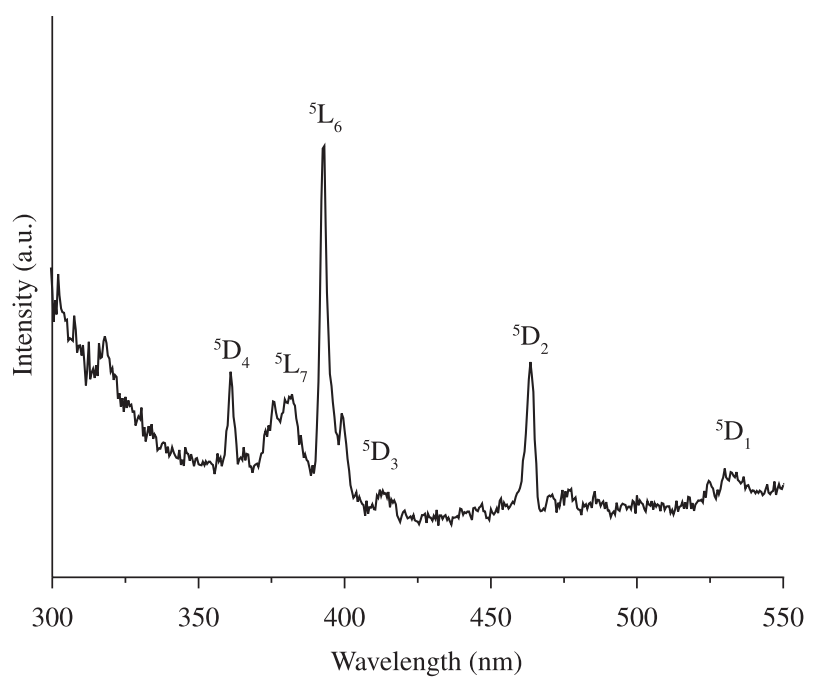

Figure 8. Excitation spectrum of the $\mathrm{Eu}^{3+}$ ion in the sample heat-treated at $1,000{ }^{\circ} \mathrm{C}$.

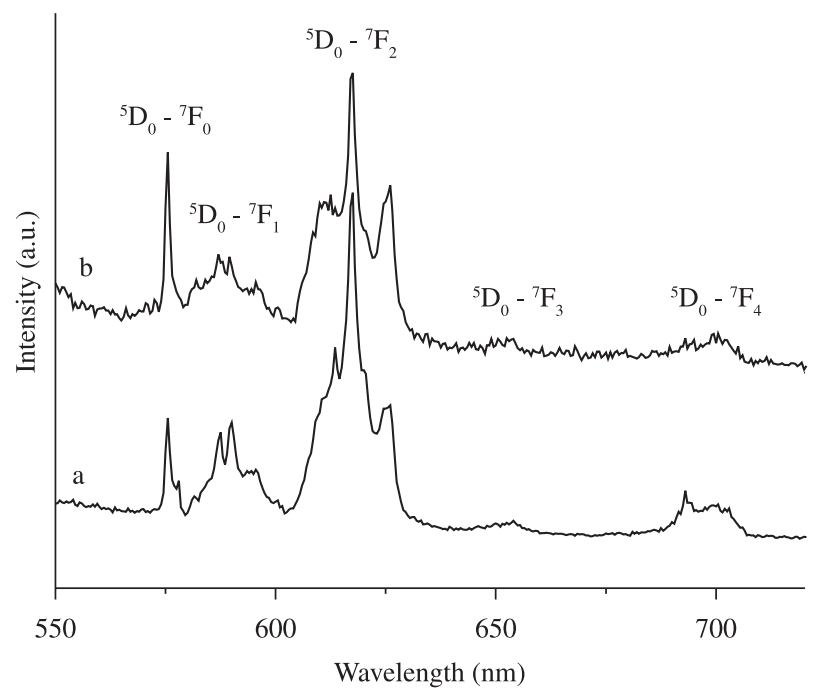

Figure 9. Emission spectra of $\mathrm{Eu}^{3+}$ ions in the sampleheat- treated at $1,000{ }^{\circ} \mathrm{C}$ and excited at: (a) $394 \mathrm{~nm}\left({ }^{5} \mathrm{~L}_{6}\right.$ level) and (b) $462 \mathrm{~nm}\left({ }^{5} \mathrm{D}_{2}\right.$ level).

of $\mathrm{Eu}^{3+}$. The large magnitude of spin-orbit coupling in the lanthanides causes the individual $\mathrm{J}$ levels of the various electronic terms to be well separated from one another, except for the ground ${ }^{7} \mathrm{~F}_{0}$ and emissive ${ }^{5} \mathrm{D}_{0}$ states of $\mathrm{Eu}^{3+}$, which are nondegenerated. The highly forbidden ${ }^{7} \mathrm{~F}_{0} \rightarrow{ }^{5} \mathrm{D}_{0}$ transition of $\mathrm{Eu}^{3+}$ is particularly important in that only a single transition is possible for a single $\mathrm{Eu}^{3+}$ ion environment ${ }^{28}$. The ${ }^{7} \mathrm{~F}_{0} \rightarrow{ }^{5} \mathrm{D}_{0}$ transition is clearly visible in Figure 8, indicating that the $\mathrm{Eu}^{3+}$ ions occupy sites without an inversion center ${ }^{29}$. The presence of nonhomogeneous sites in the material was observed based on the band-width emission ${ }^{30}$. The various $\mathrm{J}$ levels are further split by ligand fields in the maximum $2 \mathrm{~J}+1$; therefore, in the ${ }^{7} \mathrm{~F}_{0} \rightarrow{ }^{5} \mathrm{D}_{1}$ and ${ }^{7} \mathrm{~F}_{0} \rightarrow{ }^{5} \mathrm{D}_{2}$ transitions the number of bands may be 3 and 5, respectively. We observed more transitions than the ones allowed, a fact that confirmed that the $\mathrm{Eu}^{3+}$ ions occupy sites with different symmetries such as $\mathrm{C}_{n}$ ou $\mathrm{C}_{\mathrm{nv}}$. This is an indication that the calcium-fluoroaluminosilicate glass has different symmetries, which can be observed by ${ }^{27} \mathrm{Al}$ NMR.

\section{Conclusions}

The physical and chemical characteristics of glass ionomer cements render them useful and advisable for application in a variety of clinical situations. However, the industrial preparation of glass ionomer powders based on calcium-fluoroaluminosilicate glass is very expensive because it requires high temperatures, between 1,200 and $1,550{ }^{\circ} \mathrm{C}$, which makes it economically unreasonable for large-scale production. To offset this situation, the nonhydrolytic sol-gel method has proven to be efficient for the production of materials with glass properties, as shown in this work. This process allows for reaction control and the use of stoichiometric amounts of $\mathrm{Al}$ and Si reagents at low temperatures, around $110{ }^{\circ} \mathrm{C}$, thus reducing production costs.

The powder obtained by this methology was tested and showed to be a rigid cement. It was also shown that the material exhibits the basicity required for its reaction with polyacrilic acid, to form the cement.

\section{Acknowledgements}

The financial support of FAPESP, CNPq and CAPES (Brazilian research funding agencies) is gratefully acknowledged.

\section{References}

1. Mclean JW, Nicholson JW, Wilson AD. Proposed nomenclature for glass-ionomer dental cements. Quintessence International. 1994, 25(4):587-589.

2. Nicholson JW. Chemistry of glass-ionomer cements: a review. Biomaterials. 1998; 19(1):485-494.

3. Baratieri M. Procedimentos preventivos e restauradores. São Paulo: Livraria Editora Santos; 1990.

4. Mount GJ. Successful clinical performance of these materials is dependent upon careful clinical placement. Biomaterials. 1998; 19(1):573-579.

5. Moshaverinia A, Roohpour N, Darr JA, Rehman IU. Synthesis and characterisation of a novel N-vinylcaprolactam (NVC) containing acrylic acid terpolymer for applications in glass-ionomer dental cements (GIC). Acta Biomaterialia; 2009. In Press.

6. Phillips BW. Skinner Materiais Dentários. 9 ed. Rio de Janeiro: Editora Guanabara Koogan; 1993.

7. Culbertson BM. Glass-ionomer dental restoratives. Progress in Polymer Science. 2001; 26(1):577-604.

8. Stamboulis A, Law RV, Hill RG. Characterisation of commercial ionomer glasses using magic angle nuclear magnetic resonance (MAS-NMR). Biomaterials. 2004; 25(1):3907-3913.

9. Griffin SG, Hill RG. Influence of glass composition on the properties of glass polyalkenoate cements. Part II: influence of phosphate content. Biomaterials. 1999; 20(1):1579-1586.

10. Zimehl R, Hanning M. Non metallic restorative materials based on glass ionomer cements: recent trends and developments. Colloids and Surfaces, A: Physicochemical and Engineering Aspects. 2000; 163(4):55-62.

11. Navarro MFL, Pascotto RC. Cimentos de Ionômero de Vidro: aplicações clínicas em odontologia. 1 ed. São Paulo: Editora Artes Médicas; 1998.

12. Cerveau G, Corriu RJP, Lepeytre C, Mutin PH. Influence of the nature of the organic precursor on the textural and chemical properties of silsesquioxane materials. Journal of Material Chemistry. 1998; 8(4):2707-2713

13. Corriu RJP. A new trend in metal-alkoxide chemistry: the elaboration of monophasic organic-inorganic hybrid materials. Polyhedron. 1998; 17(5):925-934.

14. Bourget L, Corriu RJP, Leclercq D, Mutin PH, Vioux A. Non-hydrolytic sol-gel routes to silica. Journal of Non-Crystalline Solids. 1998; 242(1):81-91. 
15. Alfaya A, Kubota L. A utilização de materiais obtidos pelo processo de sol-gel na construção de biossensores. Química Nova. 2002; 25(5):835-841.

16. Cestari A, Bandeira LC, Calefi PS, Nassar EJ, Ciuffi KJ. Preparation of calcium fluoroaluminosilicate glasses containing sodium and phosphorus by the nonhydrolytic sol-gel method. Journal of Alloys and Compounds. 2009, 472(1):299-306

17. Wright JD, Sommerdijk NAM. Sol-Gel materials: chemistry and applications. 1 ed. Amsterdam: Gordon and Breach Science Publishers; 2001.

18. Yang Z, Lin YS. Sol-gel synthesis of silicalite/g-alumina granules. Industrial and Engineering Chemistry Research. 2000; 39(2):4944-4948.

19. Acosta S, Corriu RJP, Leclerq D, Lefervre P, Mutin PH, Vioux A. Preparation of Inorganic Oxides via a Non-Hydrolytic Sol-Gel Route. Journal of Non-Crystalline Solids. 1994; 170(1):234-244.

20. Ciuffi KJ, Lima OJ, Sacco HC, Nassar EJ. Eu ${ }^{3+}$ entrapped in alumina matrix obtained by hydrolytic and non-hydrolytic sol-gel routes. Journal of Non-Crystalline Solids. 2002; 304(1):126-133.

21. Bertolini MJ, Zaghete MA, Gimenes R, Souza RF, Vaz LG. Preparation of new glass systems by the polymeric precursor method for dental applications. Journal of Non-Crystalline Solids. 2004; 344(1):170-175.

22. Pires R, Nunes TG, Abrahams I, Hawkes GE, Morais CM, Fernandez C. Stray-field imaging and multinuclear magnetic resonance spectroscopy studies on the setting of a commercial glass-ionomer cement. Journal of Material Science: Materials in Medicine. 2004; 15(2):201-208.
23. Stamboulis A, Hill RG, Law RV. Characterization of the structure of calcium alumino-silicate and calcium fluoro-alumino-silicate glasses by magic angle nuclear magnetic resonance (MAS-NMR). Journal of Non-Crystalline Solids. 2004; 333(1):101-107.

24. Pan J, Zhang H, Pan M. Self-assembly of Nafion molecules onto silica nanoparticles formed in situ through sol-gel process. Journal of Colloid and Interface Science. 2008; 326(5):55-60.

25. Pereira PFS, Caiut JMA, Ribeiro SJL, Messaddeq Y, Ciuffi KJ, Rocha LA. et al. Microwave synthesis of YAG:Eu by sol-gel methodology. Journal of Luminescence. 2007; 126(1):378-382.

26. Nassar EJ, Ávila LR, Pereira PFS, Mello C, Lima OJ, Ciuffi KJ. et al. Nonhydrolytic sol-gel synthesis and characterization of YAG. Journal of Luminescence. 2005; 111(1):159-169.

27. Ciuffi KJ, Lima OJ, Sacco HC, Nassar EJ. $\mathrm{Eu}^{3+}$ entrapped in alumina matrix obtained by hydrolytic and non-hydrolytic sol-gel routes. Journal of Non-Crystalline Solids. 2002; 304(1):126-133.

28. Nassar EJ, Pereira PFS, Nassor ECO, Ávila LR, Ciuffi KJ, Cestari A. et al. Fenilsilicato dopado com Eu III obtido pelo método sol-gel. Química Nova. 2007; 30(7):1567-1572.

29. Sá GF, Azevedo WM, Gomes ASL. Synthesis, spectroscopy, photophysical properties and luminescence quantum yields of Europium(Iii) complexes, incorporating 2,2'- Bipyridine N,N' Dioxide. Journal of Chemistry Research. 1994; 26(2):234-237.

30. Nassar EJ, Nassor ECO, Avila LR, Pereira PFS, Cestari A, Luz LM. et al. Spherical hybrid silica particles modified by methacrylate groups. Journal of Sol-Gel Science and Technology. 2007; 43(1):21-26. 
